\title{
O USO DE DROGAS DURANTE A GESTAÇÃO E A VULNERABILIDADE DA MULHER: UM PROBLEMA DE SAÚDE PÚBLICA
}

\section{DRUG USE DURING PREGNANCY AND WOMEN'S VULNERABILITY: A PUBLIC HEALTH PROBLEM}

Milene Fernandes da Silva ${ }^{1}$

Submetido em: 10/06/2021

e26389

Aprovado em: 30/06/2021

\section{RESUMO}

Esta pesquisa teve como objetivo investigar os impactos do uso de drogas lícitas ou ilícitas, e também verificar como problemas sociais, financeiros ou emocionais influenciam pessoas ou famílias. Na ausência de alternativas de resolução a saída encontrada é a aproximação às drogas, como algo libertador dos problemas. Assim, a partir da experiência de situações vivenciadas, objetivou-se melhor compreender este aspecto da questão social, o papel do sujeito, da comunidade, da família e das políticas públicas, buscando explicitar questões que contribuam para o trabalho junto à área, na elaboração de ações que impulsionem o regaste, em especial de mulheres gestantes, que tem algum envolvimento com drogas. A pesquisa foi realizada através de levantamento bibliográfico e artigos científicos relacionados ao tema. No processo de conclusão da pesquisa, constatou-se que não há uma política somente para as gestantes que são usuárias de drogas, as políticas abrangem todo um público e a importância da família na recuperação e tratamento dos usuários dependente químico, no incentivo para que os mesmos continuem o tratamento. $\mathrm{O}$ estudo contribui significativamente para que a sociedade tenha um olhar especial à gestante usuária de drogas lícitas e ilícitas.

PALAVRAS CHAVE: Droga. Gestação. Política Pública.

\begin{abstract}
This research aimed to investigate the impacts of the use of licit or illicit drugs, and also to verify how social, financial, or emotional problems influence individuals or families. In the absence of alternative solutions, the way out is to approach drugs as a way of freeing oneself from one's problems. Thus, from the experience of lived situations, the objective was to better understand this aspect of the social issue, the role of the subject, the community, the family, and public policies, seeking to explain issues that contribute to the work in the area, in the development of actions that boost the recovery, especially of pregnant women who have some involvement with drugs. The research was carried out through a bibliographical survey where scientific articles related to the theme were used. In the process of concluding the research, we found that there is not a policy only for pregnant women who are drug users; the policies cover a whole public and the importance of the family in the recovery and treatment of drug users, in the incentive for them to continue the treatment. The study contributes significantly for society to have a special look at pregnant women who are users of licit and illicit drugs.
\end{abstract}

KEYWORDS: Drugs. Pregnandiol. Public Policy.

\footnotetext{
${ }^{1}$ Centro Universitário Internacional - UNINTER
} 


\section{RECIMA21 - REVISTA CIENTÍFICA MULTIDISCIPLINAR ISSN 2675-6218}

O USO DE DROGAS DURANTE A GESTAÇÃO E A VULNERABILIDADE DA MULHER: UM PROBLEMA DE SAÚDE PÚBLICA
Milene Fernandes da Silva

\section{INTRODUÇÃO}

O consumo de álcool e drogas, na atual sociedade brasileira, está cada vez maior, sendo as mulheres o grupo que mais cresce em adeptos. Esta constatação está fomentando em lares de família desestruturados.

O interesse em abordar este tema vem do aumento do consumo de drogas psicoativas e perceber que a mulher vem sendo cada vez mais identificada neste índice. Não é raro encontrá-la nesta situação e a preocupação aumenta quando a mulher usuária é gestante. Neste sentido, busca-se avaliar o quanto é importante a discussão do tema, apontando os perigos que o uso de drogas traz para quem a usa e também para o feto, além das consequências físico-psíquicas, familiares e sociais.

O uso de droga, nos dias de hoje, é mais que um problema social, pois está ligado diretamente no aumento dos índices de criminalidade em todos os estados brasileiros, inclusive dentro de suas casas, fator este devido ao aumento de usuários, incluindo mulheres, que muitas vezes engravidam no ápice do vício o que amplia esta questão no que tange a sociedade em um problema de questão de saúde e política (PASSINI, 2005).

Conforme Marangoni (2012), o envolvimento com drogas faz com que a pessoa se distancie inicialmente de sua família e depois da sua comunidade. Quando o vício se torna claro, as vistas de conhecidos, a dependente tende a se envolver no meio em que obtém mais drogas, e tal comportamento traz o isolamento familiar e posteriormente social. Todavia, é na família que vemos como base de um espaço privilegiado de socialização, onde nascem os valores afetivos e culturais, sendo o alicerce em que essas mulheres precisam para uma possível solução sobre a questão da dependência química e sua estabilidade emocional para poder cuidar do seu filho e/ou se cuidar.

O presente trabalho tem como objetivo principal fazer uma investigação sobre os impactos causados pelo uso de drogas durante a gestação. Para construir esta investigação, é indispensável verificar também os problemas sociais, financeiros ou emocionais que influenciam pessoas ou famílias, que têm como consequência o mundo das drogas e a vulnerabilidade social.

\section{REFERENCIAL TEÓRICO}

\subsection{Conceito e atuação das drogas no organismo humano}

A Organização Mundial de Saúde - OMS (1981), conceitua que "droga é qualquer substância que, não sendo produzida pelo organismo, tem a propriedade de atuar sobre um ou mais de seus sistemas, produzindo alterações em seu funcionamento" e define o significado de drogas psicotrópicas como "aquelas que agem no sistema nervoso central produzindo alterações de comportamento, humor e cognição, possuindo grande propriedade reforçadora, sendo passível de 


\title{
RECIMA21 - REVISTA CIENTÍFICA MULTIDISCIPLINAR ISSN 2675-6218
}

O USO DE DROGAS DURANTE A GESTAÇÃO E A VULNERABILIDADE DA MULHER: UM PROBLEMA DE SAÚDE PÚBLICA Milene Fernandes da Silva

autoadministração". Neste sentido, fica óbvio que o sujeito que faz uso de drogas psicotrópicas pode se tornar dependente.

SANCHEZ (2012) aduz que Chaloult classificou as drogas psicotrópicas da seguinte maneira:

\begin{abstract}
Estimulantes da atividade do SNC: aquelas que de maneira geral estimulam o funcionamento do nosso SNC fazendo com que a pessoa que a utilizou fique mais "ligada", agitada, "elétrica", sem sono e sem apetite. As principais drogas que pertencem a esta categoria são as anfetaminas (medicamentos para emagrecer), cocaína/crack e tabaco; Depressores da atividade do SNC: aquelas que de maneira geral diminuem o ritmo de funcionamento do SNC, fazendo com que seus consumidores fiquem mais "devagar", ou seja, "lentificados" e sonolentos. São exemplos desta classe de drogas: álcool, benzodiazepínicos (medicamentos para a ansiedade), opiáceos e inalantes; Perturbadores da atividade do SNC: aquelas que causam alterações no funcionamento cerebral quando consumidas, modificando a percepção da realidade e fazendo com que os consumidores tenham uma percepção "perturbada" de si e do meio. Esses fenômenos são parecidos aos que ocorrem em doenças mentais como as psicoses e estas drogas induzem alucinações, delírios e ilusões. São exemplos de drogas alucinógenas: LSD, ecstasy, maconha, alguns cogumelos e peiote. (SANCHEZ et al., 2012, apud CHALOULT, 1971, p. 01).
\end{abstract}

No Brasil, a legislação define como droga "as substâncias ou produtos capazes de causar dependência, assim especificados em lei ou relacionados em listas atualizadas periodicamente pelo Poder executivo da União" segundo o parágrafo único do art. $1 .^{\circ}$ da Lei n. $\stackrel{0}{11.343}$, de 23 de agosto de 2006 (Lei de Drogas). São consideradas drogas todos os produtos e substâncias listados na Portaria n. ํ SVS/MS 344/98 do Ministério da Saúde.

De acordo com o Relatório do Escritório das Nações Unidas sobre Drogas e Crime (UNODC), publicado em junho de 2016, estima-se de 5\% da população adulta, ou 250 milhões de pessoas entre 15 e 64 anos, usou pelo menos algum tipo de droga em 2014. Consumir substâncias que alteram ou modificam a consciência e comportamento humano têm sido um problema para a sociedade.

O uso destes tipos de drogas sem uma prescrição médica pode ser muito prejudicial à saúde e seu uso sem acompanhamento médico é proibido, pois a maioria tem um efeito entorpecente, alucinógeno ou até mesmo excitante, na qual o seu uso sendo indevido, pode causar certa dependência (UNODC,2016).

Conforme Sanchez (2012), as drogas ilícitas são substâncias químicas proibidas de serem produzidas, comercializadas e/ou consumidas, como por exemplo: maconha, cocaína, crack, LSD, inalantes, heroína, barbitúricos, morfina, chá de cogumelo, anfetaminas, clorofórmio, ópio e outras.

E mesmo assim alguns países permitem o uso de determinadas drogas, tendo seu uso como um feito considerado até normal, pois a grande maioria destes países, que fazem o uso dessas substâncias, seguem a cultura do país. As substâncias podem ser estimulantes, depressivas ou perturbadoras do sistema nervoso central, o que perceptivelmente altera em grande escala o organismo (FREIRE,2009). 


\section{RECIMA21 - REVISTA CIENTÍFICA MULTIDISCIPLINAR ISSN 2675-6218}

O USO DE DROGAS DURANTE A GESTAÇÃO E A VULNERABILIDADE DA MULHER: UM PROBLEMA DE SAÚDE PÚBLICA Milene Fernandes da Silva

\subsection{Legislação de política sobre drogas no Brasil}

Segundo Duarte e Branco (2009), o Brasil ainda não estabeleceu uma política de redução da demanda de drogas. Em Nova York (USA), aconteceu a XX Assembleia das Nações Unidas para discutir a demanda sobre drogas, devido a essa assembleia, surge no Brasil a secretaria Nacional Antidroga em 1998.

Até 1998, o Brasil não contava com uma política na área de redução da demanda e da oferta de drogas. Em junho daquele ano, em Nova York, durante a XX Assembleia Geral Especial das Nações Unidas, foram discutidos os princípios da redução das demandas de drogas e da responsabilidade compartilhada.

(Duarte e Branco, 2009, p 34).

Conforme as autoras Camargo e Martins (2014), as políticas públicas sociais e econômicos estão passando por modificações, segundo as pesquisas que realizaram o perfil do usuário de crack, segundo alguns pesquisadores.

Se pensarmos em políticas sociais e econômicas, ambas estão em constantes transformações, assim como perfil dos usuários de crack. Uma pesquisa quantitativa realizada em território nacional pelo grupo de pesquisadores Francisco Inácio Bastos e Neilane Bertoni, da fundação Oswaldo Cruz em parceria com a secretaria nacional de políticas sobre drogas, entre os anos de 2011 e 2013. (Camargo e Martins, 2014 p162)

Segundo Cordeiro e Laranjeira (2011) a legislação criminal passou por modificações nos últimos tempos, conforme a lei 11.343 , devido a essa modificação foram conquistados resultados importantes como a deferência entre o traficante do dependente químico.

A legislação criminal no Brasil em relação ao uso de drogas e suas consequências sofreu uma importante mudança nos últimos anos. Trata-se da lei 11.343, de 23 de agosto de 2006, mais conhecida como a nova lei antidrogas. Com ela, houve avanços em diferenciar o indivíduo que é traficante de dependentes e usuário de droga. (Cordeiro e Laranjeiras, 2011 p.439)

Conforme Camargo e Martins (2014), entre as capitais do Brasil existe uma estimativa de 370 mil usuários de crack.

Das 26 capitais brasileiras, incluindo o Distrito federal, nove regiões e municípios de médio e pequeno porte, tiveram como resultados estimados que existam aproximadamente 370 mil usuários de crack. Sendo que nessa mesma cidade, o cálculo para usuários de drogas ilícitas equivale a um milhão de pessoas, ou seja, o número de consumidores de crack corresponde a $35 \%$ das pessoas que fazem uso de drogas ilícitas nos pais. (Camargo e Martins, 2014, p 163)

Segundo Duarte e Branco (2009), a legislação brasileira sobre droga foi dirigida pelo Presidente Lula, a nova lei destaca o Brasil como articulador da prevenção para os dependentes e traficantes.

A Legislação brasileira sobre drogas foi atualizada pelo congresso nacional e sancionada pela Presidente Luiz Inácio Lula da Silva em 23 de agosto de 2006. O projeto de lei (PL) $n^{\circ} 115 / 02$ do senado tornou-se a lei $n^{\circ} 11.343 / 06$ e substituiu as leis $6.368 / 76$ e $10.409 / 02$, sobre droga, até então vigentes no país. A nova lei coloca o Brasil em destaque no cenário internacional nos aspectos relativos à 


\title{
RECIMA21 - REVISTA CIENTÍFICA MULTIDISCIPLINAR ISSN 2675-6218
}

O USO DE DROGAS DURANTE A GESTAÇÃO E A VULNERABILIDADE DA MULHER: UM PROBLEMA DE SAÚDE PÚBLICA Milene Fernandes da Silva

prevenção, atenção, reinserção social do usuário e dependente de droga, bem como ao endurecimento das penas pelo tráfico dessas substâncias. (Duarte e Branco, 2009, p.37).

Cordeiro e Laranjeiras (2011), fala que devido à lei, quando a droga é encontrada com o usuário, é o juiz que determinará sua pena, e o estado também tomará decisões cabíveis, perante problematização da droga.

\begin{abstract}
Importante ressalvar é que, com a nova lei, a prisão em flagrante para usuário de drogas deixa de existir. Para determinar se a droga encontrada se destina a consumo pessoal, o juiz avaliará a quantidade encontrada, bem como as circunstâncias locais objetivas e antecedentes dos sujeitos, ou seja, por si só, a quantidade apreendida não é fator condenatório, fica muita clara assim a intenção do estado em adotar uma postura mais educativa e preventiva no combate às drogas, utilizando penas alternativas em vez de privação da liberdade do sujeito adoecido. (Cordeiro e laranjeiras, 2011, p. 439).
\end{abstract}

Neste sentido, a verdade é que não há uma efetiva legislação ou intervenção que ampare as gestantes em situação de vulnerabilidade social. A droga traz diversos malefícios para a saúde da usuária e do feto, todavia, é um vício, é algo que a dependente necessita de ajuda profissional para não continuar nesta situação. A Lei 11.343 de 2006 institui políticas públicas com a finalidade de oferecer tratamento e reinserção social ao usuário, mas esta lei fica em sentido amplo e não especifica uma atenção especial à mulher gestante e usuária, e assim, não tem proteção.

\subsection{A IMPORTÂNCIA DA ESF NO CUIDADO COM PACIENTES GESTANTES USUÁRIAS}

\section{DE DROGAS}

O Ministério da Saúde criou a proposta de estratégia de saúde da família (ESF) com a intenção de organizar a atenção básica de saúde, objetivando um vínculo mais estreito entre os profissionais da saúde e a comunidade.

Este cuidado com o grupo familiar é o princípio desta proposta, pois visa a delimitação geográfica e procuram entender que cada comunidade tem a sua particularidade e assim, permite uma melhor compreensão sobre as necessidades de cada grupo familiar.

Neste contexto o enfermeiro está inserido como agente fundamental no processo da Unidade de Saúda da Família no qual exerce o importante papel de se desenvolver para apoiar e supervisionar o trabalho dos agentes comunitários de saúde (ACS), prestar assistências aos pacientes que necessitam de cuidados, organizar o cotidiano da ESF, planejar ações e executar atividades juntamente à comunidade.

O enfermeiro orienta a gestante e sua família, prestando informações e assistindo a gestante. Este acolhimento tem a intenção de criar uma relação de confiança entre enfermeiro e paciente para que, assim, o profissional possa prestar o melhor atendimento a gestante.

É durante o pré-natal que a equipe de saúde, principalmente o enfermeiro e médico devem mostrar a importância no manejo das situações que são abordadas, para que as necessidades identificadas através dos riscos que a 


\section{RECIMA21 - REVISTA CIENTÍFICA MULTIDISCIPLINAR ISSN 2675-6218}

O USO DE DROGAS DURANTE A GESTAÇÃO E A VULNERABILIDADE DA MULHER: UM PROBLEMA DE SAÚDE PÚBLICA Milene Fernandes da Silva

gestante possua sejam trabalhadas de forma a contemplar os benefícios em prol de uma gestação, parto e puerpério sadios. (SILVA et al, 2015, p. 44).

Quando este profissional se depara com casos de gestantes usuárias de drogas, ele precisa criar estratégias para se aproximar da gestante, explicar os danos causados pelo uso de drogas no período gestacional e acompanhar a gestante usuária de drogas para que esta se conscientize dos males que podem ser causados ao feto.

O enfermeiro está diretamente envolvido no cuidado com estas pacientes, e ele precisa ser bem capacitado para ter a sensibilidade de cativar esta gestante usuária de drogas para que a mesma siga com o pré-natal. Assim, o enfermeiro desenvolve um trabalho eficaz para com esta paciente, assim como atende às necessidades da comunidade a qual presta assistência.

\section{METODOLOGIA}

O presente artigo de revisão disserta sobre o uso de drogas durante o período gestacional. Foi realizada busca nas bases de dados Bireme, Scielo, e IMED, com acesso por meio de mídia eletrônica. Para a busca dos artigos e publicações relacionados ao tema de interesse da pesquisa, foram usados os seguintes descritores em português: mulheres usuárias de droga, gestação, políticas públicas. Pesquisar esta problemática contemporânea permitiu uma análise dos efeitos e consequências do uso de drogas por mulheres grávidas e em estado de vulnerabilidade social; o abuso de drogas lícitas durante o período gestacional e suas consequências no desenvolvimento do feto; e a importância do apoio da família e da sociedade à gestante usuária de drogas para o seu tratamento. Buscou-se, em literatura atualizada, a definição da droga e seu uso contínuo pela usuária gestante.

A busca das melhores evidências científicas disponíveis foi realizada entre as publicações ocorridas no período entre 2010 e 2017, as quais foram classificadas de acordo com o seu nível e grau de recomendação. A seleção inicial das publicações levou em conta seus títulos e resumos; quando relacionados ao assunto, buscou-se o texto completo.

Foi dada prioridade aos artigos mais recentes, aos com maior nível de evidência, às revisões narrativas e aos consensos de sociedades médicas baseados em pesquisas qualitativas e análise dos resultados. Foram encontradas 25 publicações referentes ao tema e, entre elas, selecionaram-se 12 publicações (tabela abaixo) pertinentes a esta pesquisa de revisão, que por se tratar de pesquisa bibliográfica não foi necessário que a pesquisa fosse submetida a Comitê de Ética e Pesquisa. Prezou-se por artigos publicados na área das ciências médicas e ciências humanas, pois assim o tema foi explorado de ângulos diferentes, o que foi de extrema contribuição à pesquisa.

Os artigos utilizados nesta pesquisa foram:

- Efeitos do uso de crack sobre o feto e o recém-nascido: Um estudo de Revisão;

- Uso e dependência de cocaína/crack na gestação, parto e puerpério; 


\section{RECIMA21 - REVISTA CIENTÍFICA MULTIDISCIPLINAR ISSN 2675-6218}

- Assistência pré-natal ás usuárias de drogas ilícitas;

- A importância da família na recuperação do usuário de álcool e outras drogas;

- Consequências do uso de drogas durante a gravidez;

- Aspecto da dinâmica da família com dependência química;

- Percepção da gestante sobre o consumo de drogas ilícitas na gestação;

- O uso de drogas na gravidez;

- Drogas de abuso e gravidez;

- Classificação e efeitos farmacológicos das drogas;

- O efeito das drogas nas famílias;

- Prevalência do uso de drogas de abuso por gestantes.

\section{RESULTADOS}

\subsection{O uso e abuso de drogas durante a gestação}

Segundo MENEZES et al. (2015), em seu estudo sobre as consequências do uso de drogas durante a gravidez, concluíram que $(37 ; 2,05 \%)$ das grávidas entrevistadas faziam uso de etanol, (19; $1,00 \%)$ eram fumantes, $(22 ; 1,22 \%)$ eram usuárias da maconha, $(17 ; 0,94 \%)$ faziam uso de cocaína e $(47 ; 2,61 \%)$ eram usuárias de crack, colocando em risco o desenvolvimento do feto e de sua saúde.

Neste estudo, os autores elucidaram os males que estas drogas trazem à vida da mãe e ao desenvolvimento do feto e, se faz indispensável a este trabalho, apresentar as consequências do uso das principais drogas por usuárias gestantes.

O tabaco traz um grande risco não apenas a saúde da mãe, mas principalmente ao feto e até mesmo ao recém-nascido que é amamentado pela mãe fumante. De acordo com YAMAGUCHI et al. (2007):

\footnotetext{
Os produtos derivados do cigarro, como o monóxido de carbono e a nicotina, passam facilmente pela placenta. O monóxido de carbono apresenta uma alta afinidade pela hemoglobina do feto, impedindo que esta se ligue ao oxigênio, favorecendo a hipoxemia fetal. A nicotina reduz a síntese de prostaciclinas, determinando vasoconstrição e o aumento da resistência vascular. Além disso, a placenta de mães tabagistas apresenta características sugestivas de hipoperfusão, e, como consequência, há uma maior incidência de retardo do crescimento intrauterino, descolamento prematuro de placenta e rotura prematura das membranas ovulares; Fumar no puerpério também é prejudicial ao bebê, pois os produtos do tabaco passam pelo leite da mãe, além de ocorrer diminuição de sua produção. No entanto, mesmo sendo o fumo um dos fatores de risco mais plausíveis de suspensão e redução dos efeitos sobre o feto e o recém-nascido, somente $20 \%$ das gestantes que fumam interrompem o tabagismo durante a gravidez. (YAMAGUCHI et al., 2008, p. 46)
} 


\title{
RECIMA21 - REVISTA CIENTÍFICA MULTIDISCIPLINAR ISSN 2675-6218
}

Enquanto o álcool também é um problema quando consumido demasiadamente, podendo comprometer o funcionamento do organismo e causando danos irreversíveis a quem o consome. Durante a gestação, as consequências são preocupantes:

\begin{abstract}
O etanol consumido pela gestante atravessa a barreira placentária, fazendo com que o feto seja exposto às mesmas concentrações do sangue materno. Contudo, a exposição fetal é maior, devido ao metabolismo e eliminação serem mais lentos, isso faz com que o líquido amniótico permaneça impregnado de dessa substância. Além disso, o uso e o abuso do etanol durante a gravidez está relacionado ao aumento do número de abortos e a fatores que podem comprometer o parto como, risco de infecções, deslocamento prematuro de placenta, hipertonia uterina, parto prematuro e presença de mecônio no líquido amniótico, colocando em risco a vida do feto e causando complicações na vida do recém-nascido. (MENEZES, et al., 2015, p. 02).
\end{abstract}

A maconha é a droga ilícita mais usada e isso faz com que seu uso por gestantes também seja alto e preocupante. Por ser algo conhecido por seus usuários como natural, torna o seu uso, muitas vezes, percebido de forma inocente durante a gravidez. Esta questão de ser algo natural faz com que seu consumo seja defendido por usuárias que muitas vezes acham que não influencia em sua gestação. De acordo com COUTINHO (2014, p. 17), hoje a maconha é a droga ilícita mais usada no período gestacional e este fato é preocupante porque o seu uso afeta o crescimento do feto que podem nascer com baixo peso.

De acordo com a Fundação Para Um Mundo Sem Drogas, a cocaína é uma droga na forma de pó, "extraída das folhas de coca e foi originalmente desenvolvida como um analgésico. É mais frequentemente cheirada, sendo o pó absorvido pela circulação sanguínea através dos tecidos nasais".

A cocaína é metabolizada em produtos inativos pela colinesterase plasmática. $\mathrm{Na}$ grávida, a atividade dessa enzima diminui, potencializando os efeitos adversos. Além disso, há mais conversão da cocaína à norcaína, metabólito ativo da droga. Dado o estado de hipervolemia da gestação, a vasocontrição causada pela cocaína pode precipitar crises hipertensivas. Devido às propriedades lipofílicas da cocaína, ela rapidamente atravessa a placenta por difusão simples (RIBEIRO, et al., 2011).

O crack é uma droga devastadora e causa dependência imediata. Abraham e Hess (2016), realizaram uma pesquisa sobre os efeitos do uso do crack para o feto e para o recém-nascido e em análise a Pesquisa Nacional sobre o Uso de Crack, realizada pelo Ministério da Saúde em parceria com a Fundação Oswaldo Cruz (2014), identificou que o consumo de crack e/ou similares no Brasil, somando todas as capitais e o Distrito Federal, atinge a 0,81\% da população dessas cidades, o que representaria cerca de 370 mil usuários regulares e ainda ressaltam que $20 \%$ das pessoas que frequentam locais conhecidos como "cracolândia" são mulheres. Ainda de acordo com a pesquisa, $10 \%$ dessas mulheres usuárias destes locais informaram que estão grávidas, e este fato é preocupante, uma vez que a gestante faz uso de drogas como o crack, compromete o desenvolvimento do feto, podendo causar abortos espontâneos. 


\section{RECIMA21 - REVISTA CIENTÍFICA MULTIDISCIPLINAR ISSN 2675-6218}

É importante salientar que orientar e cuidar de gestantes dependentes é extremamente complexo, uma vez que é necessário que a equipe profissional (enfermeiro, médico, assistente social) que a acompanha tenha sensibilidade e que estejam capacitados para lidar com as particularidades de cada paciente que se encontra nesta situação tão delicada.

Qualquer atitude pode fazer com que esta paciente não faça ou continue o pré-natal por questões pertinentes ao vício e como a sociedade enxerga de forma preconceituosa. É preciso que este período gestacional seja um facilitador para trazê-la ao tratamento, tendo em vista que a maioria das mães não querem que este vício prejudique o bebê.

\subsection{Família e o Dependente Químico}

Moreira (2011) traz a família como referência para tratamento da dependência química, e como base da formação do sujeito para a sociedade sendo a primeira referência da pessoa, fazendo a mediação entre o sujeito e sociedade aonde aprende a perceber o mundo e a nos situarmos nele. Mas é na família aonde tudo começa, pois, um dos motivos que leva o indivíduo a fazer o uso de álcool e droga é a falta de diálogo, desemprego, separação dos pais e por algumas regras impostas pelos pais e salienta que "os pais devem tomar cuidado com relação à liberdade atribuía aos filhos, ela não pode ser demais, porém também não pode ser de menos".

Os pais costumam dar liberdade aos filhos, por medo de prender demais, e de causar confronto entre eles, os pais podem dar a liberdade, mas dentro dos limites. A família sofre esse impacto diante do uso abusivo das drogas.

Os Pais devem formar as opiniões dos filhos caso contrário outras pessoas a formarão e pode ser que seja um traficante ou usuário de drogas, ladrão, pedófilo, prostitutas, estuprador, desocupado, delinquente, alcoólatra (Moreira 2011, p. 05).

Perante a problemática das drogas, Moreira (2011) corrobora que a influência do uso de droga e álcool começa dentro do seio familiar (próprio lar), diante dos pais ou familiares como tios, avós e primos, e isso influencia a crianças no seu futuro, até porque os pais, algumas vezes, molham a chupeta da criança na bebida.

\footnotetext{
Muitos pais quando descobrem que seus filhos estão fazendo o uso de drogas ou bebendo demais, normalmente condenam os filhos, chegando até agredi-los verbalmente e fisicamente, mas se esquecem de que tudo isso começou do incentivo que eles os próprios pais deram a seus filhos durante a sua infância. (Moreira, 2011, p. 11).
}

De acordo com as autoras Paz e Colossi (2013) a família tem o papel importante na vida do usuário quanto à recaída à proteção e à prevenção, levando em conta que a dependência química se tornou uma questão de saúde pública e social, pois o tratamento envolve internação e tratamento terapêutico. A abordagem utilizada com os usuários de drogas lícitas e ilícitas são as 


\section{RECIMA21 - REVISTA CIENTÍFICA MULTIDISCIPLINAR ISSN 2675-6218}

O USO DE DROGAS DURANTE A GESTAÇÃO E A VULNERABILIDADE DA MULHER: UM PROBLEMA DE SAÚDE PÚBLICA Milene Fernandes da Silva

internações em clínicas e em centro de tratamentos terapêuticos e psicossociais com a continuação em tratamento em grupos de apoio em CAPS AD.

Pesquisas na área de dependência química tem revelado a importância da família como fator e prevenção à recaída. Nos últimos anos, a adição e suas consequências na vida do indivíduo e sua família tem sido consideradas um problema de saúde pública. (Paz, Colossi, 2013, p. 351)

Conforme Paz e Colossi (2013) referem, dentro da família deve haver a comunicação e o aprendizado, os pais formadores de opinião e caráter, mostrando aos filhos qual o verdadeiro caminho a seguir, antes que ele, o adolescente, aprenda fora com pessoas desconhecidas, a escola e as redes sociais como apoio e suporte, também podem contribuir com a família orientando 0 adolescente.

"Os Pais devem formar as opiniões dos filhos, caso contrário outras pessoas a formarão e pode ser que seja um traficante ou usuário de drogas, ladrão, pedófilo, prostitutas, estuprador, desocupado, delinquente, alcoólatra." (Paz e Colossi, 2013, p.352).

Segundo as autoras Melo e Lima (2012), o álcool e a droga vêm crescendo lentamente, causando vários problemas para as famílias e à sociedade, esta situação vem de uma longa história de acordo com o tempo e o uso da droga que surge conforme a época de cada grupo, portanto apesar do tempo houve uma modificação no uso da droga causando problemas mais graves.

O uso do álcool e outras drogas progridem de forma lenta e insidiosa evoluindo para cronificação, acarretando imensuráveis problemas no processo saúdedoença do indivíduo, da família e da sociedade. Isso porque, termos como saúde, doença e drogas sempre estiveram presente ao longo da história da humanidade, embora cada período apresente uma maneira particular de encarar e lidar com esses fenômenos, de acordo com o conhecimento e interesses de cada época (Melo e Lima, 2012 p 85).

De acordo com a publicação do periódico de eletrônico em psicologia, a família da dependente e/ou usuária também sofre com os malefícios da droga:

A dependência química tende a afetar a família como um todo. Os filhos de usuárias de drogas possuem risco aumentado para o desenvolvimento de dependência química, futuramente, além de transtornos mentais e de problemas emocionais como baixa autoestima, fobia social, depressão, ansiedade e dificuldade de relacionamento (Melo e Lima, 2012 p 29).

O que a droga causa na saúde e na vida das pessoas é devastador. A gestante compromete a sua saúde, a saúde do feto, a estabilidade emocional e a sua vida perante a sociedade. Neste contexto, deve haver uma intervenção social e legislação que ampare as gestantes, que são vítimas desse problema social, assim como de saúde pública.

\section{CONSIDERAÇÕES FINAIS}

O consumo de drogas tem se mostrado como um dos grandes problemas de saúde pública do Brasil, sendo considerado um problema de ordem epidemiológica. Estudos têm sido 


\section{RECIMA21 - REVISTA CIENTÍFICA MULTIDISCIPLINAR ISSN 2675-6218}

O USO DE DROGAS DURANTE A GESTAÇÃO E A VULNERABILIDADE DA MULHER: UM PROBLEMA DE SAÚDE PÚBLICA
Milene Fernandes da Silva

desenvolvidos, alertando para a necessidade de se implantar políticas que previnam o ingresso dos jovens no mundo das drogas.

Infelizmente ainda é grande o número de mulheres usuárias de drogas licitas e ilícitas durante a gestação, tornando-se assim um grande problema de saúde pública. Estas mulheres que buscam na droga um alivio para seus problemas desconhecem ou nem percebem o grande malefício que o consumo desta substância causa a elas próprias, ao feto e ao recém-nascido, efeitos estes que podem se apresentar a curto e longo prazo.

Por ser este um problema tão complexo, políticas preventivas não devem depender somente de iniciativas civis. Não se quer dizer com isso, que a sociedade civil não tenha competência para desenvolver programas preventivos, tanto tem que, a maioria das iniciativas nesse sentido tem partido de entidades não governamentais.

Embora inovadora em determinados aspectos, os avanços traçados na Lei Antidrogas esbarram em muitas dificuldades. Dentre elas, destacam-se: a política repressiva como medida tradicional no campo das drogas; falta de políticas públicas que enfatizam ações preventivas no planejamento e estrutura das instituições policiais, nas esferas federal, estadual e municipal; ausência nas instituições de ensino público e privado de projetos pedagógicos voltados para a prevenção do uso indevido de drogas; dificuldades no que se refere à manutenção de dados estatísticos no banco de dados das instituições de atenção à saúde; a falta de recursos para regularizar a política de atenção aos usuários e dependentes de drogas, bem como seus familiares, junto à rede do Sistema Único de Saúde (SUS); a deficiência de recursos humanos.

A verdade é que, apesar de todo arcabouço legal apresentado, identificou-se a insuficiência no planejamento de longo prazo e nas manobras financeiras para desenvolver esse novo paradigma. Ao mesmo tempo, esse paradigma está em evolução nas diversas instituições policiais, valendo-se de experiências bem-sucedidas, mas, ressalte-se que é necessário que sejam implementadas e efetivadas em esfera nacional, não apenas iniciativas isoladas como aqui apresentadas. Em todo o caso, dada à amplitude do tema, espera-se que as ideias relatadas neste trabalho possam contribuir para esclarecer o problema, sugerir novas perspectivas e inovadoras reflexões de estudos. Neste liame, quando a gestante for usuária de drogas, é indispensável o envolvimento de uma equipe multidisciplinar para que sejam desenvolvidas estratégias de abordagem a esta gestante.

Ainda necessitamos do comprometimento do governo responsável pelas políticas públicas em atenção, prevenção e cuidado em relação ao usuário de droga, além de campanhas e ações preventivas que facilitariam ao usuário ter acesso ao tratamento da dependência química.

\section{REFERÊNCIAS}

ABRAHAM, Cláudia Flores; HESS, Adriana Raquel Binsfeld. Efeitos do uso do Crack Sobre o feto e o Recém-nascido: Um Estudo de Revisão. Revista de Psicologia da IMED, Passo Fundo, v. 8, n. 1, 


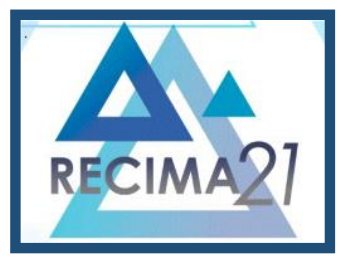

\section{RECIMA21 - REVISTA CIENTÍFICA MULTIDISCIPLINAR ISSN 2675-6218}

O USO DE DROGAS DURANTE A GESTAÇ̃̃o E A VULNERABILIDADE DA MULHER: UM PROBLEMA DE SAÚDE PÚBLICA Milene Fernandes da Silva

p. 38-51, ago. 2016. ISSN 21755027. Disponível em: https://seer.imed.edu.br/index.php/revistapsico/article/view/1045/883. Acesso em: ago. 2017.

KASSADA, Danielle Satie. et al. Prevalência do uso de drogas de abuso por gestantes. Acta paul. Enferm, São Paulo, v. 26, n. 5, p. 467-71, 2013. Disponível em: http://dx.doi.org/10.1590/S010321002013000500010 Acesso em: ago. 2017.

BALLANI, T. S.; OLIVEIRA, M. L. Uso de drogas de abuso e evento sentinela: construindo uma proposta para avaliação de políticas públicas. Texto \& Contexto Enferm, v. 16, n. 3, p. 488-94, 2017.

BOTELHO, Ana Paula Machado; ROCHA, Regina da cunha; MELO, Victor Hugo. Uso e dependência de cocaína/ crack na gestação, parto e puerpério. Revista Feminina, 2013.

COUTINHO, Tadeu et al. Assistência pré-natal às usuárias de drogas ilícitas. Disponível em: http://files.bvs.br/upload/S/0100-7254/2014/v42n1/a4808.pdf Acesso em: ago. 2017.

FREIRE, K.; PADILHA, P. C.; SAUNDERS, C. Fatores associados ao uso de álcool e cigarro na gestação. Rev Bras Ginecol Obstet, v. 31, n. 7, p. 335-41, 2009.

FREIRE, T. M.; MACHADO, J. C.; MELO, E. V.; MELO, D. G. Efeitos do consumo de bebida alcoólica sobre o feto. Rev Bras Ginecol Obstet, v. 27, n. 7, p. 376-81, 2005.

MARANGONI, S. R.; OLIVEIRA, M. L. Uso de crack por multípara em vulnerabilidade social: história de vida. Cienc Cuid Saude, v. 11, n. 1, p. 166-72, 2012.

MELO, Patrícia Freitas de; PAULO, Maria de Assunção Lima. A importância da família na recuperação do usuário de álcool e outras drogas, União de Ensino superior de Campinas GrandeUNESCO, Universidade Federal de Campinas Grande. Saúde Coletiva em Debate, dez. 2012.

MENEZES, Fernanda de Alcantara. Consequências do uso de drogas durante a gravidez. Disponível em: https://www5.bahiana.edu.br/index.php/enfermagem/article/viewFile/664/540. Acesso em: ago. 2017.

MOREIRA, Elaine. Efeito das drogas na família. [S. l: s. n.], 2011. Disponível em: http://www.semdrogas.com.br/2011/o-efeito-das-drogas-na-familia. Acesso em: ago. 2017.

ONU. Nações Unidas Brasil. 29 milhões de adultos dependem de drogas, aponta relatório do UNODC. [S. I.]: ONU, 2016. Disponível em: https://nacoesunidas.org/29-milhoes-de-adultosdependem-de-drogas-aponta-relatorio-do-unodc/. Acesso em: ago. 2017.

PASSINI JÚNIOR, R. Consumo de álcool durante a gestação. Rev Bras Ginecol Obstet, v. 27, n. 7, p. 373-5, 2005.

PAZ, Fernanda Marques; COLOSSI, Patricia Manozzo. Aspecto da dinâmica da família com dependência química. Estudos de Psicologia (Natal), v. 18, n. 4, p. 551-558, 2013. Disponível em: www.scielo.br/epsic. Acesso em: ago. 2017.

PORTELA, Graciela Lima Costa et al . Percepção da gestante sobre o consumo de drogas ilícitas na gestação. SMAD, Rev. Eletrônica Saúde Mental Álcool Drog. (Ed. port.), Ribeirão Preto, v.

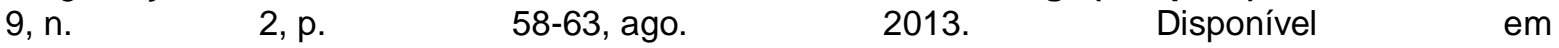
http://pepsic.bvsalud.org/scielo.php?script=sci arttext\&pid=S1806$\underline{69762013000200002 \& l n g=p t \& n r m=i s o}$. Acesso em: ago. 2017. 


\section{RECIMA21 - REVISTA CIENTÍFICA MULTIDISCIPLINAR ISSN 2675-6218}

O USO DE DROGAS DURANTE A GESTAÇÃO E A VULNERABILIDADE DA MULHER: UM PROBLEMA DE SAÚDE PÚBLICA

RIBEIRO, Christiane Carvalho et al. O uso de drogas na gravidez. RMMG Revista Médica de Minas Gerais, v, 21, n. 2, suppl 4. Disponível em: http://rmmg.org/artigo/detalhes/913. Acesso em: ago. 2017.

SANCHEZ, Zila Van Der Meer; SANTOS, Mariana Guedes Ribeiro. Classificação e efeito farmacológico das drogas. Disponível em: http://www2.unifesp.br/dpsicobio/Nova versao pagina psicobio/CAPITULO1CLASEFEITOSFARM ACOLOGICO.pdf. Acesso em: out. 2017.

YAMAGUCHI, E. T.; CARDOSO, M. M. S. C.; TORRES, M. L. A.; ANDRADE, A. G. Drogas de abuso e gravidez. Rev. Psiquiat. Clín, v. 35, n. 1, p. 44-7, 2008. 